\title{
Fair Trade?
}

The relationship between study abroad Chinese students and the United States

\author{
Mollie Dollinger \\ Indiana University \\ Bloomington, Indiana, USA \\ molliedollinger@gmail.com
}

\begin{abstract}
Despite China's $20^{\text {th }}$ century education system largely avoiding Western influences, the past 30 years has seen a reemergence of China's willingness to send students abroad. China's push to internationalize their higher education system stems from the need to alleviate the domestic competition for enrollment at top Chinese universities and also to increase a global knowledge exchange that could help to expand their economy. Western countries such as United States are also benefitting from greater revenue that international students bring and further cooperation with the emerging market of China.
\end{abstract}

Keywords-component; internationalization, higher education, study abroad

\section{INTRODUCTION}

It is not only products that Chinese economy is exporting; higher education students are also becoming increasingly international. Sending students abroad is a mutually beneficially relationship for both China and the recipient countries, including the United States. China will one day benefit from the returnees' new knowledge and technology acquisition, while the United States will benefit from the additional revenue Chinese students bring via tuition costs and infusion to the local economy. Moreover, it is a trade that both China and the United States have recognized as mutually beneficially and one that will only continue to grow in the coming years. According to the People's Daily, one of the leading newspapers in China, study abroad students have increased by at least 24\% between 2009-2011 (Enuo, 2011). This marked increased shows that China is now on the pathway to actively engage the US and the world in economics, politics, and higher education. By studying this ongoing shift in the expansion of study abroad for Chinese students as an international phenomenon, one can understand the changing nature of Chinese education today and foresee its future in education and, in general, the peaceful rise of China (Preus, 2007).

\section{BACKGROUND}

\section{A. Overview}

Until recently, the traditional Chinese education was only minimally influenced by Western knowledge (Niu, 2007). Instead the Chinese educational system of the past was based on tests, such as the Civil Service Examination. The traditional Chinese test system did not provide opportunities to stray from curriculum and students were not encouraged to be creative inside the classroom (Niu, 2007). By the late 1990's, however, China wanted to dramatically change their education system and build modern Chinese universities that could compete with the best universities abroad. The government reallocated the national budget with an extra one percent each year, for five years total, towards the goal of building and improving Chinese institutions (Duan, 2003). Yet while the infusion of money helped China modernize, the change did not grow fast enough for the large increase of Chinese students who wanted to attend university. Within China there are still only roughly 1,000 universities for a population of 1.3 billion (Jin \& Cortazzi, 2006). According to Niu (2007), only $25 \%$ of high school graduates in China will be able to attend a university due to limited capacity, making study abroad a popular consideration for many young Chinese. Also, because of the recent growth and expansion of the Chinese economy very few Chinese students abroad need to be funded by the government or depend Western scholarships, as families of students have been able to invest more in their child's future (Chen, 2011). Since it's introduction, study abroad for Chinese students has broken records, with in 2011, the number of Chinese students abroad peaking at 350,000 (Barnett \& Wu, 1995; Euro, 2011). China will only stand to benefit in this exchange. Chinese returnees can often introduce new research in fields such as engineering and science (Johnson, 2002). Altbach and Knight (2007) write that the current education climate is known as the rise of the "knowledge society" where service industries hinged upon education is essential for economic growth. Education can be viewed as an indicator of a country's current power and potential. The new massification of China's higher education and the demands/expectations exemplify its emergence as a competitor on the global knowledge economy (Van Damme, 2001).

\section{B. Destinations}

Chinese study abroad students can be found in over a hundred countries (Li \& Bray, 2007). The top destinations are the USA, UK, Canada, Germany, Australia, Japan and New Zealand (Li \& Bray, 2007). With the exception of Japan and Germany all of these destinations are favored due to their English speaking population. Chinese students have been shown to prefer English due to its dominance in fields such as science, engineering and business (Van Damme, 2001). Research also shows that Chinese students often base their decisions on where to study on international rankings of the higher education system and the specific schools they are applying for (Chen, 2007). Following academic preferences students look for destinations and university campuses that are ranked high in safety, have little history of historical 
discrimination and are located in an urban area, since most Chinese students who travel abroad reside in urban areas within China (Chen, 2007). Destination choice is often a decision made with push pull factors that weigh potential benefits with costs (Mazzarol \& Soutar, 1998). The United States may often be a top choice for Chinese students because of the reputable educational system, however, cheaper and closer options like Japan or Ireland are often more obtainable for Chinese students.

\section{EXPECTATIONS AND BENEFITS}

\section{A. Student expectations}

The study abroad phenomenon in China can be shown on both a macro and micro level. While the country as a whole benefits from the varying educational knowledge students bring back into the country, the students themselves also have high expectations of their post-graduate careers and future earning potential ( $\mathrm{Li} \&$ Bray, 2007). The top three majors for Chinese international students in the US reflect the Chinese student desire for secure, high-paying jobs: business/management, 27.5\%, engineering, $19.2 \%$, and physical/life sciences, $11.5 \%$ (Institute of International Education, 2010/2011. The decision to study abroad is often made because Chinese students believe that by receiving a globalized education they can differentiate themselves from their peers in the job market, especially since young Chinese students often struggling to find jobs that match their higher education credentials. Currently, China is home to only 27 of the top 500 universities ranked in 2012 (Academic Ranking of World Universities). By comparison, the United States has 150 universities in the top 500 (Academic Ranking of World Universities). Therefore, an above average students stands a better chance at being accepted into a foreign university of top quality, than the highly competitive universities in China. Chinese students also believe that in some fields such as science and technology, foreign universities offer superior programs (Mazzarol \& Soutar, 1998). In a survey distributed by the McKinsey Global Institute, which measures employability in the field of engineering, results showed that respondents believed $80 \%$ of US educated engineers were employable within their firms and organizations, but only $10 \%$ of Chinese educated engineers had comparable skills (Gereffi, Wadhwa, Rissing, Ong, 2008). Finally students who choose to study may also be benefitting from non-academic and non-linguistic benefits. Limited research show that by studying in a foreign country students may have an increased likelihood of confidence and personal development (Yihong, Yuan, Ying \& Yan, 2007).

Ultimately, both students and parents believe that higher education is essential for social class mobility ( $\mathrm{Li} \&$ Bray, 2007). The decision to study abroad, while financially costly, can often be seen to amplify the potential for success into higher economic brackets of society. The demand for higher education in China has reached such highs that foreign universities are now beginning to experiment with setting up long distance locations in Chinese cities (Rein, 2012). While Australia and the United Kingdom have had partnerships with Chinese institutions for years, now top tier American schools such as Duke, New York University, Stanford, and University of Southern California are all building campuses in China as well (Altbach, 2004; Rein, 2012. Foreign university appeal is equally universal for students hoping to move up in social class or students hoping to retain social class. Even the new leader of China, Xi Jinping, sends his daughter to Harvard (Rein, 2012).

\section{B. Benefits for China}

China is pursing its study abroad programs as a part of larger plan to become a more responsible stakeholder in the world. Research has shown that countries with "academic hegemony" are likely to be the same countries that hold the most political and economical power (Barnett \& Wu, 1995, p 353). Study abroad, therefore, for China reinforces academic intent to become more internationalized and has the power to stimulate the economy. Chinese parents often spend high costs for educational tutors, schools, or tuitions to help their child succeed. The China Daily reported in 2005 that the average Chinese family spends $46 \%$ of the annual expenses on their child's education in primary school, and $52 \%$ of the annual expenses when the child proceeds to higher education. The money spent on education increases significantly if the child decides to study in the US. This transaction benefits the Chinese economy directly as Chinese parents pour money into the Chinese educational market before they go abroad, and indirectly because Chinese students with study abroad experience are more likely to seek and hold jobs in international companies and the global community (Niu, 2007). Returning students are valuable resources for Chinese as they can spread Western science and technology into the larger Chinese workforce (Barnett \& Wu, 1995). Marginson (2006) writes that educational imports, such as returning study abroad students equipped with Western technology experiences and Western knowledge are key factors for keeping a strong domestic infrastructure. American educated Chinese workers can "provide a direct mechanism for transferring the skills and tacit knowledge that can dramatically accelerate industrial upgrades in developing countries" (Saxenian, 2002, p. 5). They can, moreover, prove to be a valuable resource when understanding the differences between languages and cultures.

Sending Chinese students to the US may help China improve their soft power globally as well. In a BBC media survey the United States in 2006 reported a $47 \%$ negative view on China, with only $29 \%$ of those surveyed expressing positive feelings towards China (BBC survey cited in Gill \& Huang, 2006). This was the highest level of negative views than any other developed nation. However, enrollment figures of study abroad show more and more US students are choosing to study inside China, exemplifying a shift to more positive views on China and their image.

\section{Benefits for United States}

In the United States the study abroad relationship with China has yielded more benefits in terms on economy than comparative educational advancement. Due to a diminishing of government subsides of higher education the money gained from enrolling full time Chinese students has given student mobility a reputation as an important economic trade (Li \& Bray, 2007). Marginson (2006) writes that import nations have always benefited financially from emerging nations' inability to meet the higher education demands of 
their nationals. The United States is currently the largest host country for international students (Altbach, 2004). Altbach and Knight (2007) write that the educational market including higher education commercialization is a big attraction for many universities who were previously not overtly concerned with making a profit. Especially in the current economic climate, where some departments such as fine arts and history need the revenue from more profitable departments like business, which are often popular choices for Chinese students (Van Damme, 2001). In 2003, projections already showed that international students had injected over 12 billion dollars in the US economy (Davis, 2003). Altbach and Davis note that the future direction in for-profit education will only continue to expand into areas like teaching English, test preparation and essay writing. Edwards (2007) reports that for-profit ventures are expanding globally, mimicking a form that is associated with the US educational system.

However, it is not only financially that the United States benefits from incoming Chinese students. The US can benefit from students who choose to stay in the country, especially in fields like science and engineering. Currently science and engineering graduates are in demand due to skill shortages and the US aging workforce (Johnson, 2002). Saxenian (2002) writes, "by becoming transnational entrepreneurs, these immigrants can provide the critical contacts, information, and cultural know-how that link dynamic- but distant- regions in the global economy" (p.3). Even students who choose to return to China will often reinforce positive feelings towards the United States, helping the US reputation in China (Johnson, 2002).

\section{PROBLEMS}

\section{A. Problems: Political and Economic}

As beneficial as study abroad can be for both host and sending nations, it can also be a process fraught with complications. It was not too long ago that the attacks of September 11th and subsequent government foreign policies threatened to eliminate the United States as a study abroad designation. After September 11th foreign student enrollment in higher education dropped as much as $10 \%$ for three following years (Chen, 2005). This drop took place despite higher education institutions continuing in the hopes of enrolling more foreign students as the root of the problem actually was many foreign students were unable to obtain the necessary visas needed to entry the United States (Chen, 2007).

The study abroad phenomenon in China has also led to a continuing disparate between social classes. Given the shortage of available seats in top higher education institutions within China, the increasingly large and well educated middle class is becoming more competitive than ever before. Those who can study abroad are often privileged making the decision to study abroad a political one, juxtaposing the have and have nots. The New York Times published a series of articles in 2012 pushing the issue of "Democratic Education" in China. It reads, "China evidently has long struggled with the issue of educational access and equity, ranging from dramatic political movements to demographic realities of rural-urban change.
Who gets educated will remains one of the central issues of education in China for the foreseeable future.... Democratic education in this context refers to education that has open access and equal opportunity, but always with the preservation of a strong core of high quality into which only those who can qualify may enter... In a country of 1.3 billion people, there are just 2.5 million university places" (Tao, Berci, He, 2012).

The marketization of higher education, both with the high cost of study abroad and tuition fees for Chinese domestic universities leaves many rural or lower class students unable to enroll even if they do meet the criteria (Jin \& Cortazzi, 2006). Chinese academics might also fear an unequal distribution of wealth and power. Global economic forces in China are affecting the salary of Chinese professors and staff, who are no longer satisfied with their wages against the current inflation of price of goods and standards of living (Yang, 2004). If China does not find a way to slowly increase the pay of those who work- and are exceptionalwithin the higher education system, professors and staff might leave for the commercial sector which in turn could drastically affect the quality of university system as a whole (Yang, 2004).

Not all students who study abroad want to return to China after they graduate often resulting in brain drain. Students instead may prefer staying abroad because they perceive there to be a lack of academic or scientific jobs in their home countries (Hao \& Suedfeld, 1998). Ironically, the 1990s policy initiatives that pushed so many Chinese students into majors like engineering and science also resulted in a decrease medium pay for these jobs given the surplus of qualified applicants. However, these same jobs in the West often can pay double the average monthly pay in China (Gereffi, Wadhwa, Rissing, Ong, 2008). Jobs in emerging economies like China that do exist are often only commercial centered sectors and unappealing to students who want to work in research and development (Hao \& Suedfeld, 1998). Johnson (2002) found that countries that do not offer attractive science and technology policies, like China, often suffer from a low return rate of students. The results show that students are China and India are far less likely to return to their home countries post study abroad than students from more academically friendly countries such as South Korea and Taiwan (Johnson, 2002).

\section{B. Problems: Social Learning, Language and Culture}

Research has also found that students of different diverse backgrounds may prefer different learning styles. Chinese students may not be as cognitively developed to match Western styles of learning due to the lack of opportunity in high school to practice critical thinking skills, decisionmaking and participation in extracurricular activities (Zhang \& Watkins, 2001). In a study done by Ramburuth and McCormick (2001) results showed variation between Australian and Asian students in their approaches to learning and different learning styles. Asian students reported higher levels of deep motivation and showed a preference for group work, while Australians reported higher levels of surface motivation and were overall less collaborative than their Asian classmates (Ramburuth \& McCormick, 2001). These differences may make it difficult for Asian students to easily 
adapt to Western universities and styles of learning. Studies have also shown that Chinese students are most familiar with learning centered around a textbook as opposed to learning without a core book to follow along (Douglas, Douglas, Barnes, 2006). For US higher education classes that do not use a textbook the learning process in the classroom can often times be confusing or disorganized.

In China, universities run differently than in countries like the US. The US system of learning often requires general courses followed by a major selection- which can be changed later on if the student changes their mind. Meanwhile universities in China require students predetermine their major before enrolling and courses are very specialized to a particular skill or topic (Zhang \& Watkins, 2001). Therefore, for Chinese students studying in the US now given far more power in their own decision making ability the context can be stressful and perhaps overwhelming.

Since Chinese students work more collectively and come from different learning backgrounds than US students there have also been concerns over academic honesty with Chinese students studying in the US. Results from a study in Taiwan showed of the 2,068 students surveyed over $60 \%$ of students admitted to participating in academic dishonesty (Lin \& Wen, 2007). The results also showed that the same percentage of students did not believe such behaviors was unethical, showing that in fact there are many cultural differences within the subject. If Chinese students want to go abroad and succeed it could be an obstacle for them to understand the ethics behind university rules if they are going to adhere to the same ethical standards. In 2006, the academic science world of China including many top scientists and universities leaders, admitted to widespread academic dishonesty within their ranks (Xin, 2006). The Ministry of Education (MOE) promised to investigate and many universities fired professors and assistant professors that were found guilty of publishing unethical work, but the current extent of the problem within all of China still need more research (Xin, 2006).

Foreign students have to be English proficient in both their areas of studies and their social lives, which often require two entirely different sets of vocabulary. Chinese students studying in Western universities must tackle knowledge delivery via lectures, where students must listen, write and comprehend all the material in a second language simultaneously. Research has shown that English proficiency is the biggest indicator of international student success, more than motivation, age, or learning communities (Andrade, 2006). Despite this many top schools in the US have only recently begun to require English proficiency tests, instead encouraging students whose English level is not proficient enough to participate in extra, costly English program before starting the regular curriculum. One professor from Indiana University (ranked 11th in enrollment of international students for the 2011/2012 academic year) wrote in the local paper, "The simple truth is that we are letting in students who cannot speak English and we are letting them get through university without even minimal English skills. I had students in upper level course not able to understand my questions, let alone respond to it. It's an embarrassment, and it drags a whole class down (Leonard, 2012, Blooming Herald Times).

Study abroad can offer a limited view of a foreign country. Noda (2007) writes that because study abroad takes place when the learner is already an adult, the prior knowledge and associations with the host country can impede on the experience and ultimately the ability to change the learner's international perspective. Noda continues that study abroad is likely only to affect the learner in certain contexts not on a grand scale of worldwide cultural knowledge. In a study of American students studying abroad Younes and Asay (2003) found that much more cultural knowledge was acquired unintentionally by being exposed to the new culture rather than intentionally introduced by the university or student contexts. Results also showed that many of the students abroad felt overwhelmed in the course of their time away and mentioned the quick pace was stressful and they did not have enough time for reflection (Younes \& Asay, 2003).

\section{Problems: Quality}

Altbach and Knight (2007) note that the massification of higher education and study abroad today has expanded with little attention being paid to accreditation process and overall quality concerns. Internationalization of higher education is instead too often motivated by profit, and as such, has progressed without concern on developing resources and materials specialized for internationally minded curriculum that meets the needs of a diverse student body (Van Damme, 2001). In the early 2000s America set up several off shore campuses in Israel looking for an economic gain, however, the quality was poor and Israel ha since closed the schools and shifted their attention away from foreign collaboration. Given the US higher educations hopes to further collaboration with China, lack of quality concerns could result in negative exchanges. Some researchers argue that study abroad exchange is only marginalizing the other, not increasing mutual respect and communication between cultures and institutions (Yang, 2004).

Due of this inequity in internationalization concerns have risen about second or third world countries assimilating their educational system to mirror the West. This would cause higher education worldwide to morph and homogenize, perhaps leading to a plateau of educational development (Knight \& De Wit, 1997, as cited in Yang, 2004). Other effects of academic homogenization include language. With English as the highly favored second language in China, Asian students are choosing not to study other languages, signifying a decline in their popularity (baronet \& Wu, 1995). If this continues at a strong pace certain communities may become marginalized if they do not transition to English.

\section{CONCLUSION}

As China's economy grows, the middle class continues to want more for their children, especially in terms of education. For the US, this means tangible economic and intellectual benefits from the increase of Chinese students studying within the higher education system. The trade, therefore, helps the US higher education system which is currently in need for more funding, while also helping Chinese students 
gain the knowledge needed to compete internationally. Overall, the trade is beneficial for both parties that can continue to signify the growing positive relationship between the US and China and the peaceful rise of China as a world power.

\section{REFERENCES}

[1] Altbach, P.G. (2004). Higher education crosses borders: Can the United States remain the top destination for foreign students?. Change: the magazine of higher learning, 36(2), 18-25.

[2] Altbach, P.G., \& Knight, J. (2007). The internationalization of higher education: Motivations and realities. Journal of Studies in International Education, 11(3- 4), 290-305.

[3] Altbach, P. \& Davis, T. (1999) 'Global Challenge and National Response: Notes for an International Dialogue on Higher Education', in Altbach, P. and Peterson, P. (eds) Higher Education in the 21st Century: Global Challenge and National Response, IIE Research Report Number 29, Institute of International Education and the Boston College Centre for International and Higher Education, Annapolis, pp. 3-10.

[4] Andrade, M.S. (2006). International students in English-speaking universities adjustment factors. Journal of Research in International Education, 5(2), 131-154.

[5] Barnett, G.A., \& Wu, R. Y. (1995). The international student exchange network: 1970 \& 1989. Higher Education, 30(4): 353-368.

[6] Bray, M., \& Qin, G. (2001). Comparative education in greater China: Contexts, characteristics, contrasts and contributions. Comparative Education, 37(4), 451-473.

[7] Chang, M. J. (1996). Racial diversity in higher education: Does a racially mixed student population affect educational outcomes? (Doctoral dissertation, University of California, Los Angeles).

[8] Chen, L.H. (2007). Choosing Canadian graduate schools from afar: East Asian students' perspectives. Higher Education, 54(5): 759-780.

[9] Chen, S. (2011, April). Chinese overseas students hit record high. BBC Online. Retrieved from http://www.bbc.co.uk/news/world-asiapacific-13114577

[10] Chen, Y. P. (2005). Skill-sorting, self-selectivity, and immigration policy regime change: Two surveys of Chinese Graduate students' intention to study abroad. The American Economic Review, 95(2): 6670.

[11] China Daily. (2005). Retrieved from http://www.china.org.cn/english/Life/124528.htm

[12] Van Damme, D. (2001). Quality issues in the internationalisation of higher education. Higher Education: 41(4): 415-441.

[13] Davis, T. M. (2003). Atlas of student mobility.

[14] Duan, X. R. (2003). Chinese Higher Education Enters a New Era. Academe, 89(6): 22-27.

[15] Douglas, J., Douglas, A., \& Barnes, B. (2006). Measuring student satisfaction at a UK university. Quality Assurance in Education: 14(3): 251-257.

[16] Edwards, J. (2007). Challenges and opportunities for the internationalization of higher education in the coming decade: Planned and opportunistic initiatives in American institutions. Journal of Studies in International Education, 11(3-4), 373-381.

[17] Enuo, Zhao. (2011, December 19). 350,000 Chinese students to study abroad in 2011. People's Daily. Retrieved from http://english.peopledaily.com.cn/203691/7681454.html

[18] Gereffi, G., Wadhwa, V., Rissing, B., Ong, R. (2008). Getting the numbers right: International engineering education in the United States, China, and India. Journal of Engineering Education, 97(1), 13-25.

[19] Gill, B., \& Huang, Y. (2006). Sources and limits of Chinese 'soft power.' Survival, 48(2): 17-36.

[20] Gu, M. (2001). Education in China and abroad: perspectives from a lifetime in comparative education. (Vol. 9). Comparative Education Research Centre.
[21] He, Q. (2002). Academic Freedom in China. Academe, 88(3): 26-28.

[22] Hoskisson, R.E., Eden, L., Lau, C.M., \& Wright, M. (2000). Strategy in emerging economies. Academy of management journal, 249-267.

[23] Ismail, B., Morgan, M., \& Hayes, K. (2006). Effect of short study abroad course on student openness to diversity. Journal of Food Science Education, 5(1), 15-18.

[24] Jin, L., \& Cortazzi, M. (2006). Changing practices in Chinese cultures. Language, Culture and Curriculum, 19(1), 5-20

[25] Johnson, J. M. (2002). Reverse Brain Drain and the Global Diffusion of Knowledge, The. Geo. J. Int'l Aff., 3, 125.

[26] Leonard, M. (2012). IU's international enrollment up, but not without concerns. HeraldTimesOnline.com.

[27] Li, M., \& Bray, M. (2007). Cross-border flows of students for higher education: Push-pull factors and motivations of Mainland Chinese students in Hong Kong and Macau. Higher Education, 53(6), 791818.

[28] Lin, C. H. S., \& Wen, L. Y. M. (2007). Academic dishonesty in higher education- a nationwide study in Taiwan. Higher Education, 54(1), 85-97.

[29] Marginson, S. (2006). Dynamics of national and global competition in higher education. Higher Education, 52(1), 1-39.

[30] Mazzarol, T., \& Soutar, G. N. (2002). The "Push-pull" factors influencing international student destination choice. International Journal of Educational Management, 16(2), 82-90.

[31] Niu, W. (2007). Western influences on Chinese educational testing. Comparative Education, 43(1), 71-91.

[32] Noda, M. (2007). Performed Culture: Cataloguing Culture Gains during Study Abroad. Japanese Language and Literature, 41(2), 297314.

[33] Preus, B. (2007). Educational trends in China and the United States: Proverbial pendulum or potential for balance? The Phi Delta Kappan, 89(2), 115-118.

[34] Ramburuth, P. \& McCormick, J. (2001). Learning diversity in higher education: A comparative study of Asian international and Australian students. Higher Education, 43, 333-350.

[35] Saxenian, A. (2002). Transnational communities and the evolution of global production networks: the cases of Taiwan, China and India. Industry and Innovation, 9(3), 183-202.

[36] Tao, L., Berci, M., \& He, W. (2012). China Rises Companion: Study Abroad. New York Times. Retrieved from http://www.nytimes.com/ref/college/coll-china-education-003.html.

[37] Xin, H. (2006). Scandals shake Chinese science. Science, 312(5779), 1464-1466.

[38] Yang, R. (2004). Openness and reform as dynamics for development: a case study of internationlisation at South China university of technology. Higher Education, 47(4), 473-500.

[39] Yao, L. (2004). The Chinese overseas students: An overview of the flows change. Population and Society: Issues, Research, Policy. $12^{\text {th }}$ Biennial Conference. Australian Population Association.

[40] Yihong, G.; Yuan, Z., Ying, C., \& Yan, Zhou. (2007). Relationship between English learning motivation types and self-identity change among Chinese students. TESOL Quarterly, 4I(1), 133-155.

[41] Younes, M., \& Asay, S. (2003). The world as a classroom: the impact of international study experiences on college students. College Teaching, 51(4), 141-147.

[42] Zhang, L., \& Watkins, D. (2001). Cognitive development and student approaches to learning: an investigation of Perry's theory with Chinese and US university students. Higher Education, 41(3), 239261.

[43] Zhao, D. (1996). Foreign study as a safety-valve: the experience of China's university students going abroad in the eighties. Higher Education, 31(2), 145-163. 